\title{
Colonic necrosis due to calcium polystyrene sulfonate (Kalimate) not suspended in sorbitol
}

\author{
María Dolores Castillo-Cejas ${ }^{1}$, Inés de-Torres-Ramírez ${ }^{2}$ and Carmen Alonso-Cotoner ${ }^{1}$ \\ ${ }^{\prime}$ Neuro-Immuno-Gastroenterology Group. Digestive Diseases Research Unit. Department of Gastroenterology. Institut de \\ Recerca (VHIR). Hospital Universitari Vall d'Hebron. Universitat Autònoma de Barcelona, Spain. Centro de \\ Investigación Biomédica en Red de Enfermedades Hepáticas y Digestivas (CIBERehd). ${ }^{2}$ Department of Pathology. \\ Institut de Recerca (VHIR). Hospital Universitari Vall d'Hebron. Universitat Autònoma de Barcelona, Spain
}

\begin{abstract}
Cation-exchange resins are used in the management of hyperkalemia, particularly in patients with end-stage renal disease. These resins were associated with gastrointestinal tract lesions, especially sodium polystyrene sulfonate (Kayexalate) mixed with sorbitol. We present a case of colonic necrosis after the administration of calcium polystyrene sulfonate (Kalimate) not suspended in sorbitol.
\end{abstract}

Key words: Ischemic colitis. Necrosis. Kalimate. Sorbitol.

\section{CASE REPORT}

A 73-year- old man with history of dyslipidemia treated with statins, coronary artery disease treated with aspirin, transdermal nitrates and $\beta$-blockers, hyperuricemia treated with allopurinol and bilateral inguinal herniorrhaphy the prior week receiving analgesic treatment with acetaminophen and tramadol was admitted to our hospital with lower gastrointestinal bleeding during a dialysis session. He suffered from end-stage renal disease and was receiving dialysis 3 times a week, and treatment with calcium poly-

Castillo-Cejas MD, De-Torres-Ramírez I, Alonso-Cotoner C. Colonic necrosis due to calcium polystyrene sulfonate (Kalimate) not suspended in sorbitol. Rev Esp Enferm Dig 2013;105:232234.

Received: 01-10-2012

Accepted: 19-11-2012

Correspondence: M. ${ }^{a}$ Dolores Castillo Cejas. Department of Digestive Diseases. Hospital Universitari Vall d'Hebron. Passeig Vall d'Hebron, 119-129. 08035 Barcelona, Spain

e-mail: mdcastillo@vhebron.net styrene sulfonate not suspended in sorbitol. On admission, the hemoglobin level was $6.5 \mathrm{~g} / \mathrm{dL}$ despite 4 units of packed red blood cells had been transfused before admission. He presented with hypotension, so urgent computerized tomography $(\mathrm{CT})$ scan with intravenous contrast was performed and did not find active bleeding. He subsequently received an esophago-gastroduodenoscopy examination that revealed a large hiatal hernia without other findings. A colonoscopy showed ischemic lesions in cecum, ascending colon and hepatic angle, and biopsies were performed. Histological examination of the tissue revealed mucosal necrosis and Kalimate crystals within the granulation tissue from one of the colonic ulcers. Lower gastrointestinal bleeding stopped under conservative treatment, and the patient was discharged from the hospital 8 days after admission.

\section{DISCUSSION}

Cation-exchange resins are widely used to treat hyperkalemia, mostly in patients with end-renal stage disease but also in patients with hyperkalemia resulting from other diseases. Calcium polystyrene sulfonate (Kalimate) is one of these cation-exchange resins. When Kalimate reaches the intestinal lumen, calcium ion of Kalimate is exchanged for potassium ion that is therefore excreted into the feces. Unlike sodium polystyrene sulfonate (Kayexalate), Kalimate does not cause an increase in serum sodium and phosphate levels, so it can be used in sodium-restricted patients, and neither reduces calcium levels (1). It can be administered orally or as an enema preparation. Initially, these resins were suspended in water, but later they were mixed with sorbitol as a cathartic to avoid fecal impaction and bezoar formation. However, the association with sorbitol is not exempt from complications, and several cases of ischemic colitis related to this association have been reported. In 1987, Lillemoe et al. presented a case series of 5 uremic 
patients who suffered colonic necrosis shortly after receiving sodium polystyrene sulfonate in sorbitol enemas for the treatment of hyperkalemia (2). These findings were experimentally reproduced in rats and subsequently reported in end-stage renal disease patients, demonstrating that uremia could favor necrosis development (3). Later, similar findings were described in postoperative renal-transplant patients (4) and postoperative patients in general, as well as in patients with hyperkalemia (5) and premature newborn (6). The most extensive case series was reported by Rashid et al. in 1997, describing also for the first time involvement of the upper gastrointestinal tract in patients treated with Kayexalate given orally (7), although these lesions were less severe and were not associated with an increase in mortality or surgery, in contrast to colonic affection (8). Lower gastrointestinal tract involvement usually causes bloody diarrhea due to colonic transmural wall affection, so differential diagnosis has to exclude other similar diseases such as ischemic colitis per se, opportunistic infection (especially in immunossuppressed patients) or pseudomembranous colitis. However, rectal stenosis due to foreign body response to Kayexalate has also been reported (9). Involvement of other organs when orally administered, such as lung, has also been described, causing aspiration pneumonia, especially in patients with altered mental status or swallowing disorders (10).

Although pathophysiology of this clinical entity has not been fully elucidated, both sorbitol and resin crystals have been involved in the development of gastrointestinal lesions (11). Sorbitol-induced lesions have been related to its hyperosmotic load, leading to ATP-dependent $\mathrm{Na}^{+}-\mathrm{K}^{+}$pumps dysfunction in the intestinal mucosa, alteration of cellular membrane transport systems regulating cellular volume (3), and reduced intestinal blood flow due to vasoconstriction phenomena. In contrast, crystal deposit within the intestinal wall may directly damage the intestinal mucosa. Moreover, many contributing factors can favor the development of intestinal ischemia. In end-stage renal disease patients, elevated renin levels predispose to mesenteric vasoconstriction. Other contributing conditions include hypotension resulting from hemodialysis-induced hypovolemia or vascular disease with reduced intestinal blood flow (12).

Histologic features include transmural necrosis, and ulcerations containing resin crystals that can also be present in the lumen, or on the serosal surface if perforation occurs $(7,8)$. On microscopic examination, crystals stain red with periodic acid-Schiff (PAS) stain and Ziel-Neelsen stain, and display a characteristic crystalline mosaic pattern that distinguish them from cholestyramine crystals. The microscopic appearance of Kalimate crystals is the same as Kayexalate crystals (1) (Fig. 1).

In September 2009, the frequency of severe adverse events reported leads the FDA to remove recommendations for concomitant administration of these resins in sorbitol. However, although most reports refer to gastrointestinal lesions following administration of these resins mixed with sorbitol, gastrointestinal lesions have also been described

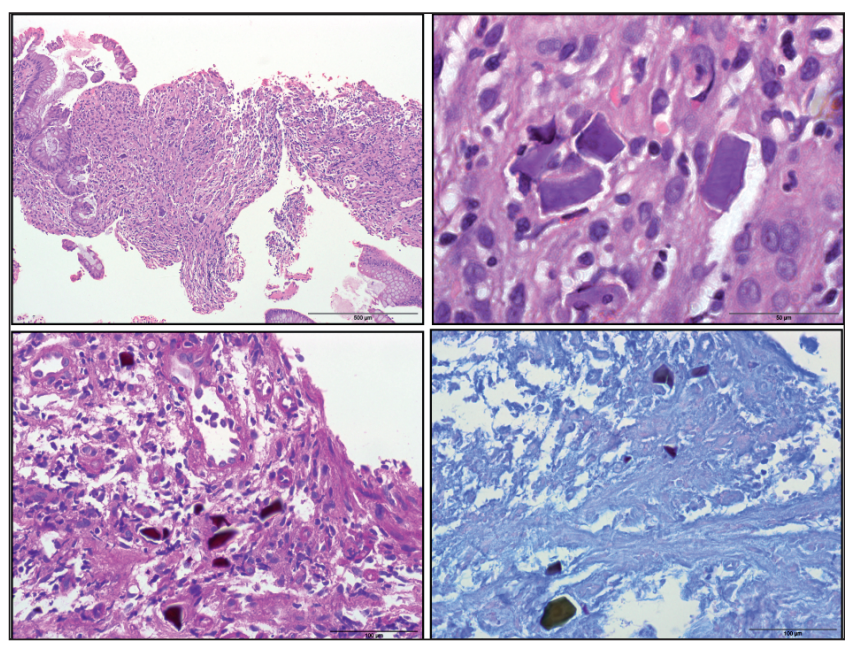

Fig. 1. A. Microscopically, intestinal mucosa shows ischemic changes and the presence of dense polygonal basophilic crystals within the granulation tissue and the ulcer bed (x200HE). B. Calcium polystyrene sulfonate crystals with their characteristic mosaic pattern within the ulcer bed $(\mathrm{x} 40 \mathrm{OHE})$. C. Kalimate crystals stain red with periocid acid-shiff (PAS) stain and refractile with Ziel-Neelsen stain (D).

after administration of sorbitol-free resins. Kayexalate not mixed with sorbitol has been associated with the development of ileal (11) and colonic (13) ischemic lesions with varying degrees of severity. Recently, Rugolotto et al. described a necrotizing enterocolitis in a premature newborn after receiving sorbitol-free sodium polystyrene sulfonate as an enema (14). Although less frequent, gastrointestinal lesions related to sorbitol-free Kalimate administration, given orally or as an enema, have also been reported $(1,15)$. Similar to Kayexalate, the severity of lesions varies, including transmural necrosis and perforation of the gastrointestinal tract. In all reports, Kalimate crystals within the intestinal mucosa were found.

This case confirms that Kalimate per se induces ischemic intestinal injury, mostly in reduced blood flow situations, such as a hemodialysis. In conclusion, in patients with vascular risk factors, benefit-risk evaluation of single or chronic administration of calcium/sodium polystyrene sulfonate, either orally or as an enema, should be carefully performed to avoid life threatening adverse events.

\section{REFERENCES}

1. Joo M, Bae WK, Kim NH, Han SR. Colonic mucosal necrosis following administration of calcium polystryrene sulfonate (Kalimate) in a uremic patient. J Korean Med Sci 2009;24:1207-11.

2. Lillemoe KD, Romolo JL, Hamilton SR, Pennington LR, Burdick JF, Williams GM. Intestinal necrosis due to sodium polysterene (Kayexalate) in sorbitol enemas: Clinical and experimental support for the hypothesis. Surgery 1987;101:267-72.

3. Gardiner GW. Kayexalate (sodium polystyrene sulphonate) in sorbitol associated with intestinal necrosis in uremic patients. Can J Gastroenterol 1997;11:573-7. 
4 Scott TR, Graham SM, Schweitzer EJ, Bartlett ST. Colonic necrosis following sodium polyterene sulfonate (Kayexalate)-sorbitol enema in a renal transplant patient. Report of a case and review of the literature. Dis Colon Rectum 1993;36:607-9.

5. Dardik A, Moesinger RC, Efron G, Barbul A, Harrison MG. Acute abdomen with colonic necrosis induced by Kayexalate-sorbitol. South Med J 2000;93:511-3.

6. Bennett LN, Myers TF, Lambert GH. Cecal perforation associated with sodium polysterene sulfonate-sorbitol enemas in a 650 gram infant with hyperkalemia. Am J Perinatol 1996;13:167-70.

7. Rashid A, Hamilton SR, Stanley R. Necrosis of the gastrointestinal tract in uremic patients as a result of sodium polyterene sulfonate (Kayexalate) in sorbitol: An underrecognized condition. Am J Surg Pathol 1997;21:60-9.

8. Abraham SC, Bhagavan BS, Lee LA, Rashid A, Wu T-T. Upper gastrointestinal tract injury in patients receiving Kayexalate (sodium polystyrene sulfonate) in sorbitol. Clinical, endoscopic and histopathologic findings. Am J Surg Pathol 2001;25:637-44.

9. Chatelain D, Brevet M, Manaouil D, Yzet T, Regimbeau JM, Sevestre $\mathrm{H}$. Rectal stenosis caused by foreign body reaction to sodium polystyrene sulfonate crystals (Kayexalate). Ann Diagn Pathol 2007;11:217-9.
10. González-Cuyar LF, Cresswell NB, Burke AP. Sodium polystyrene sulfonate (Kayexalate) aspiration. Pathology 2008;3:27.

11. Aguilera B, Alcaraz R. Necrosis intestinal asociada a la administración de sulfonato de poliestireno sódico: presentación de un caso. Rev Esp Patol 2000;33:171-4

12. Kelsey PB, Chen S, Lauwers GY. Case 37-2003: A 79 year-old man with coronary artery disease, peripheral vascular disease, end-stage renal disease, and abdominal pain and distention. N Engl J Med 2003;349:2147-55.

13. Hourseau M, Lagorce-Pages C, Benamouzig R, Tuil O, Ecomard MA, Zemoura $\mathrm{L}$, et al. Ulceration colique après administration prolongée de Kayexalate ${ }^{\circledR}$ (polystyrene sulfonate de sodium); Gastroenterol Clin Biol 2004;28:311-3.

14. Rugolotto S, Gruber M, Solano PD, Chini L, Gobbo S, Pecori S. Necrotizing enterocolitis in a 850 gram infant receiving sorbitol-free sodium polystyrene sulfonate (Kayexalate): Clinical and histopathologic findings. J Perinatol 2007;27:247-9.

15. Lee SH, Kim SJ, Kim GE, Lee WJ, Hong WK, Baik GH, et al. Calcium polystyrene sulfonate induced colonic necrosis in patient with chronic kidney disease. Korean J Gastroenterol 2010;55:261-5. 